\title{
Arctigenin inhibits human breast cancer cell proliferation, migratory and invasive abilities and epithelial to mesenchymal transition by targeting 4EBP1
}

\author{
WENFANG LUO, FEI WANG, HEWEI LUO and HUI LIU \\ Department of Traditional Chinese Medicine, The First Affiliated Hospital of \\ University of South China, Hengyang, Hunan 421001, P.R. China
}

Received March 26, 2020; Accepted December 17, 2020

DOI: $10.3892 /$ etm.2021.9979

\begin{abstract}
Breast cancer (BC) is one of the most common types of cancer with the highest morbidity rate amongst all cancers in women worldwide. Arctigenin is isolated from the seeds of Asteraceae lappa and exhibits anti-inflammatory and anti-viral effects. The present study aimed to investigate the effect of arctigenin on $\mathrm{BC}$ cells and to explore the regulation of arctigenin on eukaryotic translation initiation factor $4 \mathrm{E}$ binding protein 1 (4EBP1) expression. To do so, MDA-MB-231 and BT549 cells were treated with arctigenin at various concentrations $(0,5,10,20$ and $40 \mu \mathrm{M})$. Cells treated with $40 \mu \mathrm{M}$ arctigenin were transfected with pcDNA3.1-4EBP1 or NC control. Cell Counting Kit-8 assay was used to determine cell proliferation, reverse transcription quantitative PCR was used to evaluate the transfection efficiency, western blotting was used to detect relative protein expression and Transwell assays were performed to evaluate the migratory and invasive abilities of BC cells. The results demonstrated that arctigenin could inhibit the proliferation, migratory and invasive abilities, and epithelial to mesenchymal transition (EMT) of MDA-MB-231 and BT549 cells. Furthermore, arctigenin downregulated the expression of 4EBP1 in MDA-MB-231 and BT549 cells, whereas 4EBP1 overexpression could reverse the inhibiting effect of arctigenin on proliferation, migratory and invasive abilities, and EMT in MDA-MB-231 and BT549 cells. The findings suggested that arctigenin may inhibit human BC cell proliferation, migratory and invasive abilities, and EMT by targeting 4EBP1.
\end{abstract}

Correspondence to: $\mathrm{Mr}$ Hui Liu, Department of Traditional Chinese Medicine, The First Affiliated Hospital of University of South China, 69 Chuanshan Road, Hengyang, Hunan 421001, P.R. China

E-mail: liuhui1AH@126-web.net

Key words: arctigenin, eukaryotic translation initiation factor $4 \mathrm{E}$ binding protein 1

\section{Introduction}

Breast cancer (BC) is one of the most common and deadly cancers in women worldwide (1-3), and >20 distinct subtypes of breast cancer have been identified (4). Next-generation sequencing studies have drawn comprehensive molecular BC portraits, and $>1600$ driver mutations have been identified in 93 BC genes (5). Among all cases, hormone-receptor-positive BCs account for half of the disease subtypes (6). According to the presence or absence of molecular markers for estrogen or progesterone receptors and human epidermal growth factor 2 (ERBB2; formerly HER2), BC is divided into three major subtypes (luminal, basal-like and Her- $2^{+}$) (7). The subtype would determine the type of systemic therapy given to patient, including endocrine therapy, chemotherapy, and ERBB2-targeted antibody or small-molecule inhibitor therapy combined with chemotherapy (8). In addition, surgical resection is also considered for patients with non-metastatic $\mathrm{BC}$ (9). At present, palliative care can improve the quality of life and prolong the life in patients with metastatic BC treated according to subtypes (10). It is therefore necessary to identify new therapeutic targets and to determine the underlying mechanisms of $\mathrm{BC}$.

Arctigenin, a bioactive lignin, can be isolated from the seeds of Asteraceae lappa and has exhibited some anti-inflammatory and anti-viral effects (11). Furthermore, arctigenin has been reported to increase the chemosensitivity of several cancer cells, including HepG2, HeLa and K562 (12). Arctigenin has also been applied to the treatment of various types of cancer, and the anti-tumor function has been illustrated in various cancers, including gallbladder cancer (13), human retinoblastoma cells (14), lung cancer (15) and prostate tumor (16). Wang et al (17) reported that arctigenin could trigger autophagy, induce apoptosis and enhance the sensitivity of colorectal cancer cell to chemotherapy. In addition, arctigenin can inhibit the migratory and invasive abilities of breast cancer cells by downregulating heparanase and matrix metalloproteinases (MMPs) 2 and 9 in MDA-MB-231 cells (18). Huang et al (12) also demonstrated that arctigenin could promote the anti-metastasis effect and inhibit triple-negative breast cancer by downregulating the protein cancerous inhibitor of protein phosphatase $2 \mathrm{~A}$. In addition, it 
was demonstrated that arctigenin can target the transcription factor signal transducer and activator of transcription 3, which is involved in epithelial to mesenchymal transition (EMT) (19). However, limited studies have focused on the underlying mechanism of arctigenin on metastasis, migration and EMT in BC.

Eukaryotic translation initiation factor $4 \mathrm{E}$ binding protein 1 (4EBP1) is a type of translation-repressor protein and represents one of the main downstream effector of mammalian target of rapamycin (mTOR) (20). As a tumor suppressor, 4EBP1 serves crucial roles in various types of cancer. For example, 4EBP1 can be reactivated by mTOR inhibition and act as a tumor suppressor in head and neck squamous cell carcinomas (21). Furthermore, overexpressed 4EBP1 is an independent predictor of outcome for patients with ovarian cancer (22). There is also some evidence that 4EBP1 is overexpressed in BC cells where it might serve as an oncogene $(23,24)$. However, the underlying mechanism of 4EBP1 in $\mathrm{BC}$ remains unknown.

Therefore, the present study aimed to investigate the effect and underlying mechanisms of arctigenin on BC cells and to explore the regulation relationship between arctigenin and $4 \mathrm{EBP} 1$.

\section{Materials and methods}

Chemicals and reagents. Arctigenin (purity, up to 98\%) was obtained from Shanghai Yuanye Bio-Technology Co., Ltd. Arctigenin was dissolved in DMSO at a stock solution of $50 \mathrm{mM}$ and stored at $-20^{\circ} \mathrm{C}$. The solution was then diluted in culture medium to the appropriate final concentrations prior to use $(5,10,20$ and $40 \mu \mathrm{M})$.

Cell treatment and transfection. The human breast cancer cell lines MDA-MB-231 and BT549 were purchased from the American Type Culture Collection. Cells were cultured in DMEM (Gibco; Thermo Fisher Scientific, Inc.), containing 10\% FBS (Gibco; Thermo Fisher Scientific, Inc.), and $100 \mu \mathrm{g} / \mathrm{ml}$ streptomycin and $100 \mathrm{U} / \mathrm{ml}$ penicillin (Gibco; Thermo Fisher Scientific, Inc.) and placed at $37^{\circ} \mathrm{C}$ in a humidified incubator containing 5\% $\mathrm{CO}_{2}$. MDA-MB-231 and BT549 cells were treated with arctigenin at various concentrations $(5,10,20$ and $40 \mu \mathrm{M}$ ) or vehicle as the control for 24,48 and $72 \mathrm{~h}$.

For 4EBP1 overexpression, $50 \mathrm{nM}$ pcDNA3.1-4EBP1 or pcDNA3.1-NC (Invitrogen; Thermo Fisher Scientific, Inc.) were diluted by $250 \mu \mathrm{l}$ of serum-free Opti-MEM and incubated at room temperature for $5 \mathrm{~min}$ and mixed with $5-\mu 1$ aliquot of Lipofectamine $^{\circledR} 3000$ (Invitrogen; Thermo Fisher Scientific, Inc.) for another $20 \mathrm{~min}$ at room temperature and added to culture well of MDA-MB-231 or BT549 cell $\left(5 \times 10^{4} /\right.$ well). Subsequently, the cells were cultured for $6-8 \mathrm{~h}$ at $37^{\circ} \mathrm{C}$ with $5 \% \mathrm{CO}_{2}$, the complete medium was refreshed and the cells were cultured for a further $48 \mathrm{~h}$ prior to the following experiments.

Cell proliferation assay. MDA-MB-231 and BT549 cells were seeded at the density of $5 \times 10^{3}$ cells per well in 96-well plates and cultured in DMEM medium containing 10\% FBS overnight. Subsequently, cells were treated with different concentrations of arctigenin and cultured for various times (24, 48 and 72 h). Cell Counting Kit-8 (CCK8; $10 \mu \mathrm{l}$; Dojindo
Molecular Technologies, Inc.) reagent, which was used to assess cell proliferation, was added to the wells and cells were incubated for $3 \mathrm{~h}$ at $37^{\circ} \mathrm{C}$. Absorbance was measured at a wavelength of $450 \mathrm{~nm}$ on a microplate reader.

Transwell migration and invasion assay. To evaluate the migratory and invasive abilities of cells, 24-well Transwell chambers (8- $\mu \mathrm{m}$ pore size; Corning Inc.) were used. MDA-MB-231 and BT549 cells were treated with different concentrations of arctigenin for $48 \mathrm{~h}$. For the migration assay, $1 \times 10^{5}$ treated cells were resuspended in serum-free medium containing $1 \%$ bovine serum albumin (Sigma-Aldrich; Merck KGaA) and seeded in the upper chamber of the Transwell, while DMEM with $10 \%$ FBS was added to the lower chamber. After incubation at $37^{\circ} \mathrm{C}$ for $24 \mathrm{~h}$, cells in the lower chamber were fixed with $4 \%$ paraformaldehyde and stained with $1 \%$ crystal violet for $15 \mathrm{~min}$ at $37^{\circ} \mathrm{C}$ (JRDUN Biotechnology Co., Ltd.), whereas cells in the upper wells were removed. For the invasion assay, the method was similar to the cell migration assay, but the Transwell membrane was pre-treated with Matrigel (BD Biosciences) at a concentration of $2 \mathrm{mg} / \mathrm{ml}$. In addition, the results were assessed $36 \mathrm{~h}$ after incubation. For qualification, five random fields per filter were counted under a light microscope at a magnification of x100 (Leica Microsystems GmbH).

$R N A$ extraction and reverse transcription quantitative (RT-q) $P C R$. MDA-MB-231 and BT549 cells were collected and total RNA was extracted using TRIzol ${ }^{\circledR}$ reagent (Invitrogen; Thermo Fisher Scientific, Inc.). PrimeScript RT reagent Kit (Takara Biotechnology Co., Ltd.) was used for reverse transcription. RT-qPCR was conducted with SYBR green master reagent (Toyobo Life Science). The PCR reactions were conducted as follows: Initial denaturation at $95^{\circ} \mathrm{C}$ for $2 \mathrm{~min}$ followed by 28 cycles at $95^{\circ} \mathrm{C}$ for $30 \mathrm{sec}, 58^{\circ} \mathrm{C}$ for $30 \mathrm{sec}$, and $72^{\circ} \mathrm{C}$ for $30 \mathrm{sec}$. The sequences of the primers used were as follows: 4EBP1, forward 5'-GATACCTCCTTGTGCCTC CA-3', reverse 5'-TCGTTCTTGTCCACTTCCTG-3'; and GAPDH, forward 5'-ATCCCATCACCATCTTCCAG-3' and reverse 5'-TTCTAGACGGCAGGTCAGGT-3'. The relative expression levels of 4EBP1were normalized to endogenous control GAPDH and were expressed as $2^{-\Delta \Delta \mathrm{Cq}}(25)$.

Western blotting. Western blotting was performed to detect the protein expression of E-cadherin, N-cadherin, vimentin and 4EBP1. Cells were harvested, washed with PBS and lysed in RIPA buffer (Sigma-Aldrich; Merck KGaA) and $1 \%$ protease inhibitors cocktail (Merck KGaA). Protein concentration was determined using BCA protein reagent (Pierce; Thermo Fisher Scientific, Inc.). Proteins $(20 \mu \mathrm{g})$ were separated by $10 \%$ SDS-PAGE gel and transferred onto PVDF membranes (Merck KGaA). Membranes were blocked with $5 \%$ skimmed milk for $1 \mathrm{~h}$ at $37^{\circ} \mathrm{C}$ and were incubated overnight at $4^{\circ} \mathrm{C}$ with primary antibodies against E-cadherin (cat. no. ab1416; 1:100), N-cadherin (cat. no. ab76057; 1:1,000), vimentin (cat. no. ab92547; 1:1,000), 4EBP1 (cat. no. ab32024; 1:5,000) and GAPDH (cat. no. ab181602; 1:10,000; all from Abcam). Membranes were then incubated with a diluted horseradish peroxidase-labeled goat anti-rabbit secondary antibody (cat. no. SE134; 1:2,000, Beijing Solarbio Science and Technology Co., Ltd.) at room temperature for $1 \mathrm{~h}$. 
SuperSignal ${ }^{\circledR}$ West Pico Trial kit (Pierce; Thermo Fisher Scientific, Inc.) was used to detect the signal on the membrane and optical densities of the bands were measured using Image J software (version 1.38; National Institutes of Health).

Statistical analysis. Statistical analyses were performed using SPSS 22.0 software (IBM Corp.). The data were presented as the means \pm standard deviation. Comparison among three or more groups was conducted using one-way ANOVA followed by Tukey's post-hoc test. $\mathrm{P}<0.05$ was considered to indicate a statistically significant difference.

\section{Results}

Arctigenin inhibits the proliferation of MDA-MB-231 and BT549 cells. CCK-8 assay was used to measure the proliferation of MDA-MB-231 and BT549 cells treated with arctigenin $(0,5,10,20$, and $40 \mu \mathrm{M})$ for 24,48 and $72 \mathrm{~h}$. As presented in Fig. 1A and B, arctigenin significantly decreased the proliferation of MDA-MB-231 and BT549 cells in a concentration-dependent manner compared with the control. Subsequently, the concentrations of 20 and $40 \mu \mathrm{M}$ were selected to further evaluate the effects of arctigenin on the migratory and invasive abilities and EMT of cells.

Arctigenin inhibits the migratory and invasive abilities and EMT of MDA-MB-231 and BT549 cells. As presented in Fig. 2A, the migration ability of MDA-MB-231 and BT549 cells following treatment with 20 and $40 \mu \mathrm{M}$ arctigenin was significantly decreased compared with the control. Furthermore, the migration ability of MDA-MB-231 and BT549 cells treated with $40 \mu \mathrm{M}$ arctigenin was significantly decreased compared with cells treated with $20 \mu \mathrm{M}$ arctigenin. The results from Fig. 2B demonstrated that arctigenin could also inhibit the invasive ability of MDA-MB-231 and BT549 cells in a concentration-dependent manner. In addition, as presented in Fig. 2C, the protein expression of $\mathrm{N}$-cadherin and vimentin was significantly decreased in MDA-MB-231 and BT549 cells following treatment with 20 and $40 \mu \mathrm{M}$ arctigenin compared with the control. The expression of E-cadherin was significantly increased in MDA-MB-231 and BT549 cells. These results demonstrated also that arctigenin may inhibit EMT in a dose-dependent manner. Taken together, these findings indicated that arctigenin may serve a crucial role in the processes of migration, invasion and EMT of MDA-MB-231 and BT549 cells.

Arctigenin downregulates the expression of $4 E B P 1$ in $M D A-M B-231$ and BT549 cells. The effect of arctigenin on 4EBP1 expression in BC cells was evaluated. As seen in Fig. 3, the expression of 4EBP1 was significantly decreased in MDA-MB-231 and BT549 cells following treatment with 20 and $40 \mu \mathrm{M}$ arctigenin compared with the control. In addition, 4EBP1 expression in cells treated with $40 \mu \mathrm{M}$ arctigenin was significantly decreased compared with cells treated with $20 \mu \mathrm{M}$ arctigenin.

$4 E B P 1$ overexpression can reverse the inhibitory effect of arctigenin on the proliferation, migratory and invasive abilities and EMT in MDA-MB-231 and BT549 cells. The
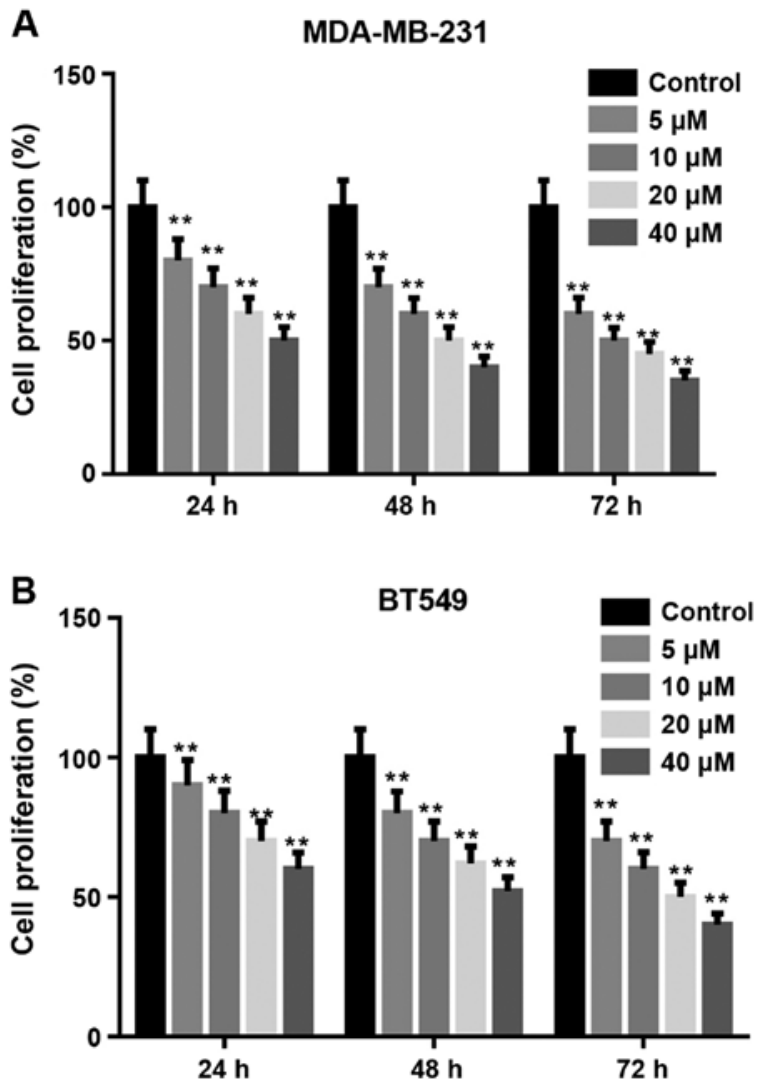

Figure 1. Arctigenin inhibited the proliferation of MDA-MB-231 and BT549 cells. (A and B) Proliferation of MDA-MB-231 and BT549 cells treated with arctigenin $(0,5,10,20$, and $40 \mu \mathrm{M})$ for 24,48 or $72 \mathrm{~h}$ detected by Cell Counting-Kit 8 assay. ${ }^{* *} \mathrm{P}<0.01$ vs. Control group.

effect of 4EBP1 on cell migratory and invasive abilities and EMT in MDA-MB-231 and BT549 cells was subsequently further investigated. 4EBP1 was overexpressed by transfection with pcDNA-4EBP1, and the transfection efficiency was examined by RT-qPCR and western blotting. As presented in Fig. 4A, the mRNA and protein expression of 4EBP1 was significantly increased in transfected MDA-MB-231 and BT549 cells compared with NC. Furthermore, MDA-MB-231 and BT549 cell proliferation was significantly decreased following treatment with arctigenin, which was reversed following 4EBP1 overexpression (Fig. 4B). The results from Transwell assays demonstrated that 4EBP1 overexpression could reverse the inhibitory effect of arctigenin on the cell migratory and invasive abilities (Fig. 4C and D). In addition, 4EBP1 overexpression significantly increased the expression of E-cadherin but decreased the expression of N-cadherin and vimentin in MDA-MB-231 and BT549 cells treated with arctigenin (Fig. 4E). These findings suggested that overexpression of 4EBP1 may reverse the inhibitory effect of arctigenin on the proliferation, migratory and invasive abilities and EMT in MDA-MB-231 and BT549 cells.

\section{Discussion}

$\mathrm{BC}$ is one of the most prevalent carcinomas in women worldwide, and the development of $\mathrm{BC}$ metastasis leads to a high mortality rate. However, there is no Food and Drug Administration-approved targeted therapy for BC (26). It is 
A
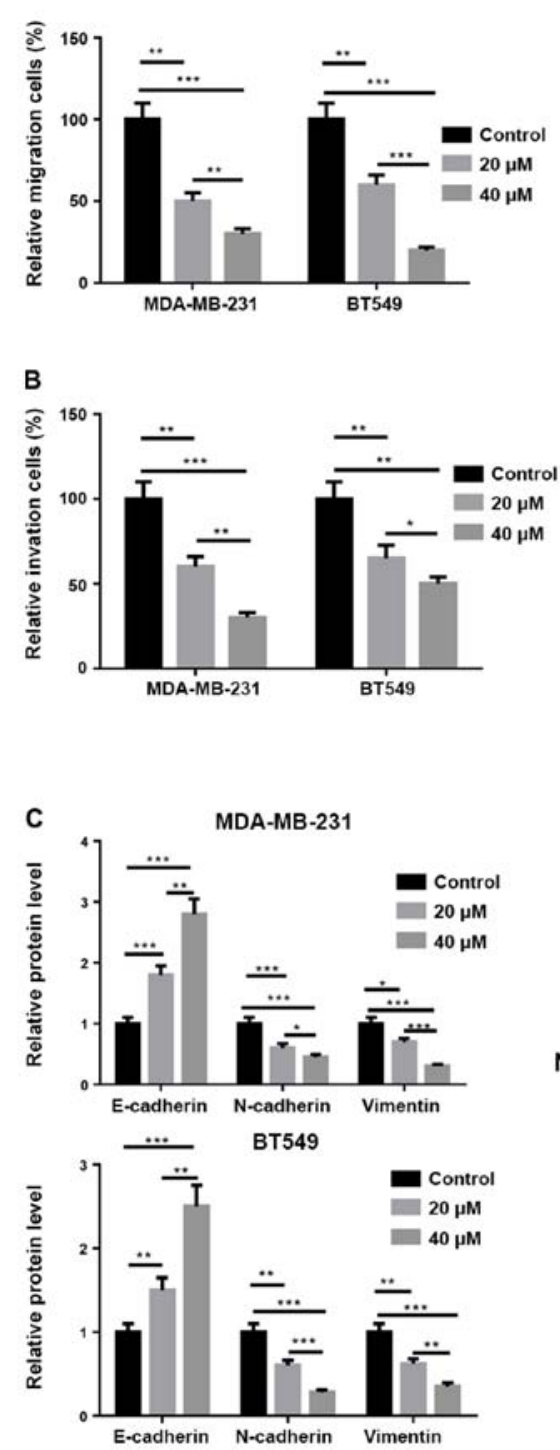
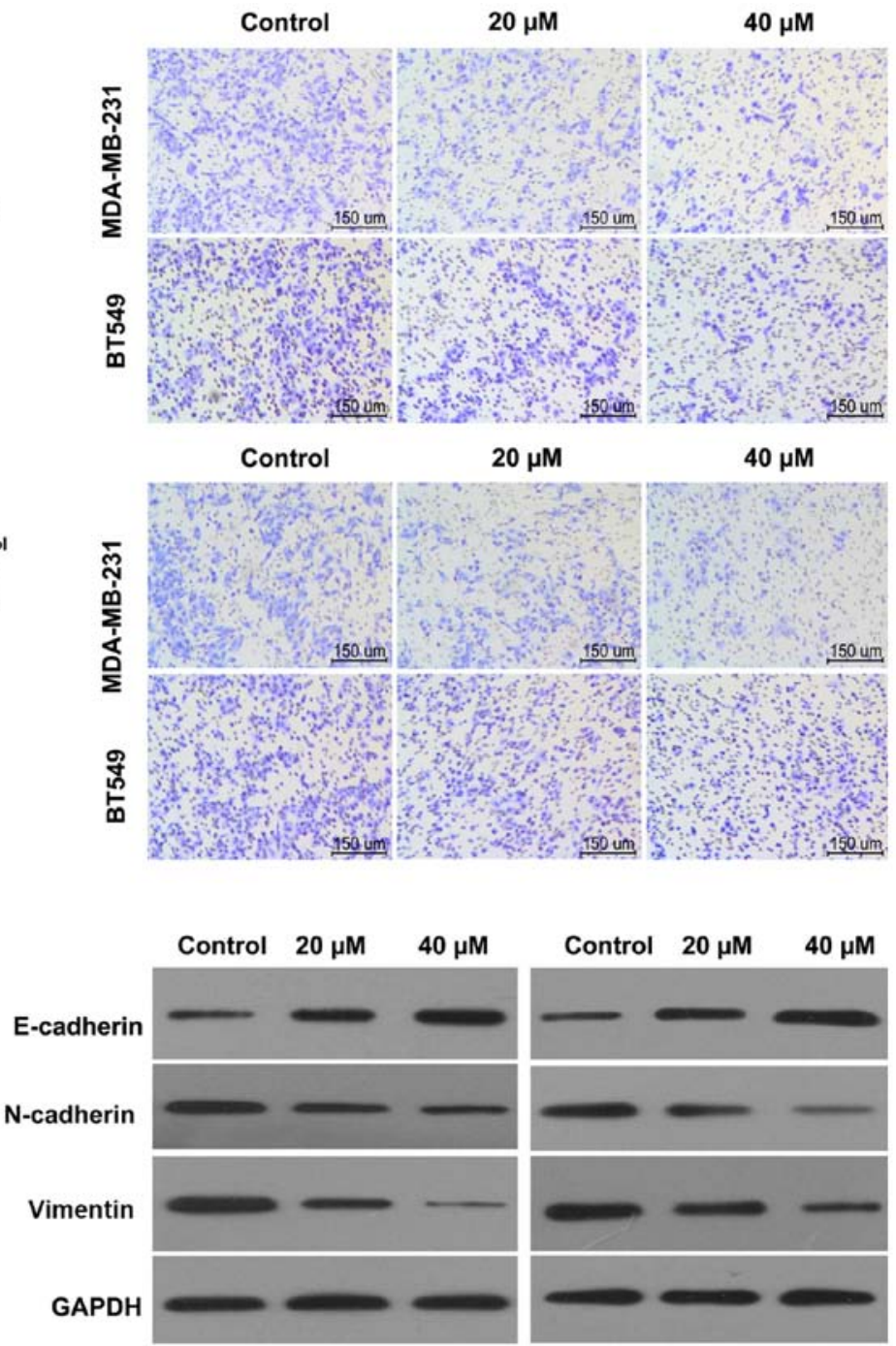

MDA-MB-231

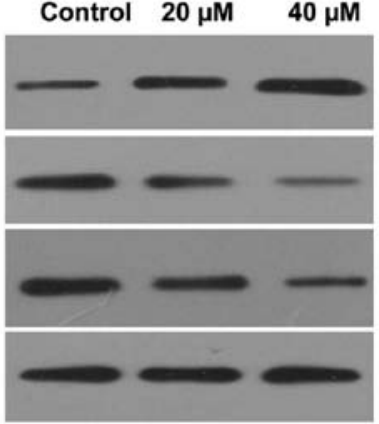

BT549

Figure 2. Arctigenin inhibited the migratory and invasive abilities and EMT of MDA-MB-231 and BT549 cells. (A) Migratory ability of MDA-MB-231 and BT549 cells treated with arctigenin assessed by Transwell assay (scale bar, $150 \mu \mathrm{m}$ ). (B) Invasive ability of MDA-MB-231 and BT549 cells treated with arctigenin assessed by Transwell assay (scale bar, $150 \mu \mathrm{m}$ ). (C) Protein expression of N-cadherin and vimentin in MDA-MB-231 and BT549 cells treated with arctigenin evaluated by western blotting. " $\mathrm{P}<0.05{ }^{* *} \mathrm{P}<0.01$ and ${ }^{* * * *} \mathrm{P}<0.001$ vs. Control group or $20 \mu \mathrm{M}$ group.

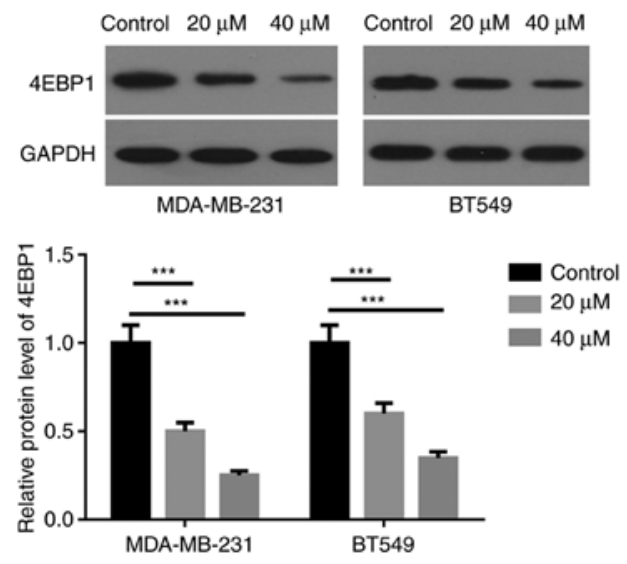

Figure 3. Arctigenin downregulated the expression of 4EBP1 in MDA-MB-231 and BT549 cells. Protein expression of 4EBP1 in MDA-MB-231 and BT549 cells treated with arctigenin was assessed by western blotting and quantified by densitometric analysis. ${ }^{* * * *} \mathrm{P}<0.001$ vs. Control group. therefore urgent to identify new targeting therapy and drugs against BC. In the last decades, arctigenin and 4EBP1 have been reported in several studies. As previously reported, arctigenin inhibits the degradation of topoisomerase II $\alpha$ and reduces the expression of GRP78 in solid tumors, which can attenuate anticancer drug resistance (27). Maheshwari et al (28) also found that arctigenin shows anti-tumor activity against a set of human solid tumor cell lines, including pancreatic-PANC-1, colon-H116, lung-H125, liver-HepG2, OVC-5 and brain-U251N. However, the role and underlying mechanism of arctigenin and 4EBP1 in the proliferation, migratory and invasive abilities and EMT of BC cells remain unclear. The present study demonstrated that arctigenin could inhibit the proliferation, migratory and invasive abilities and EMT of BC cells, which was reversed following 4EBP1 overexpression.

Arctigenin is a member of the Asteraceae family that could inhibit the growth of several cancer cells (29). Previous studies 
A
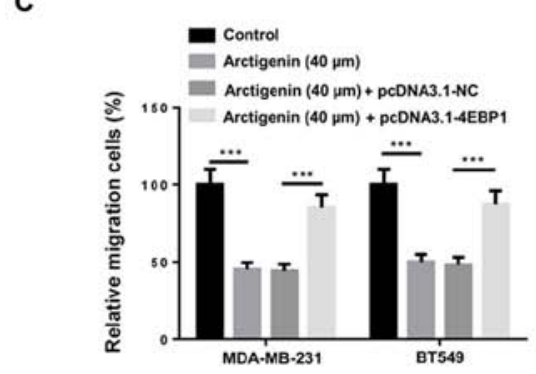

D
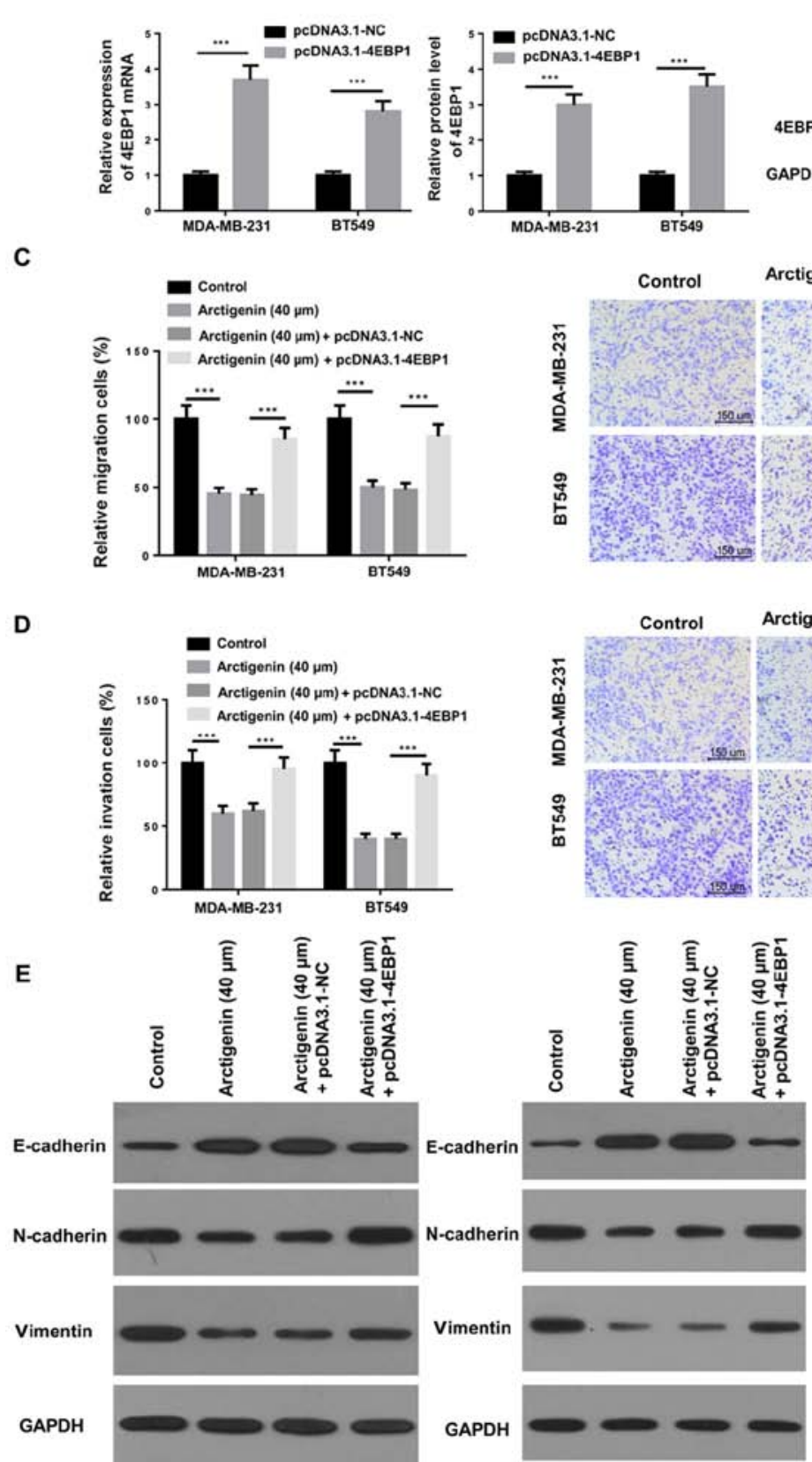
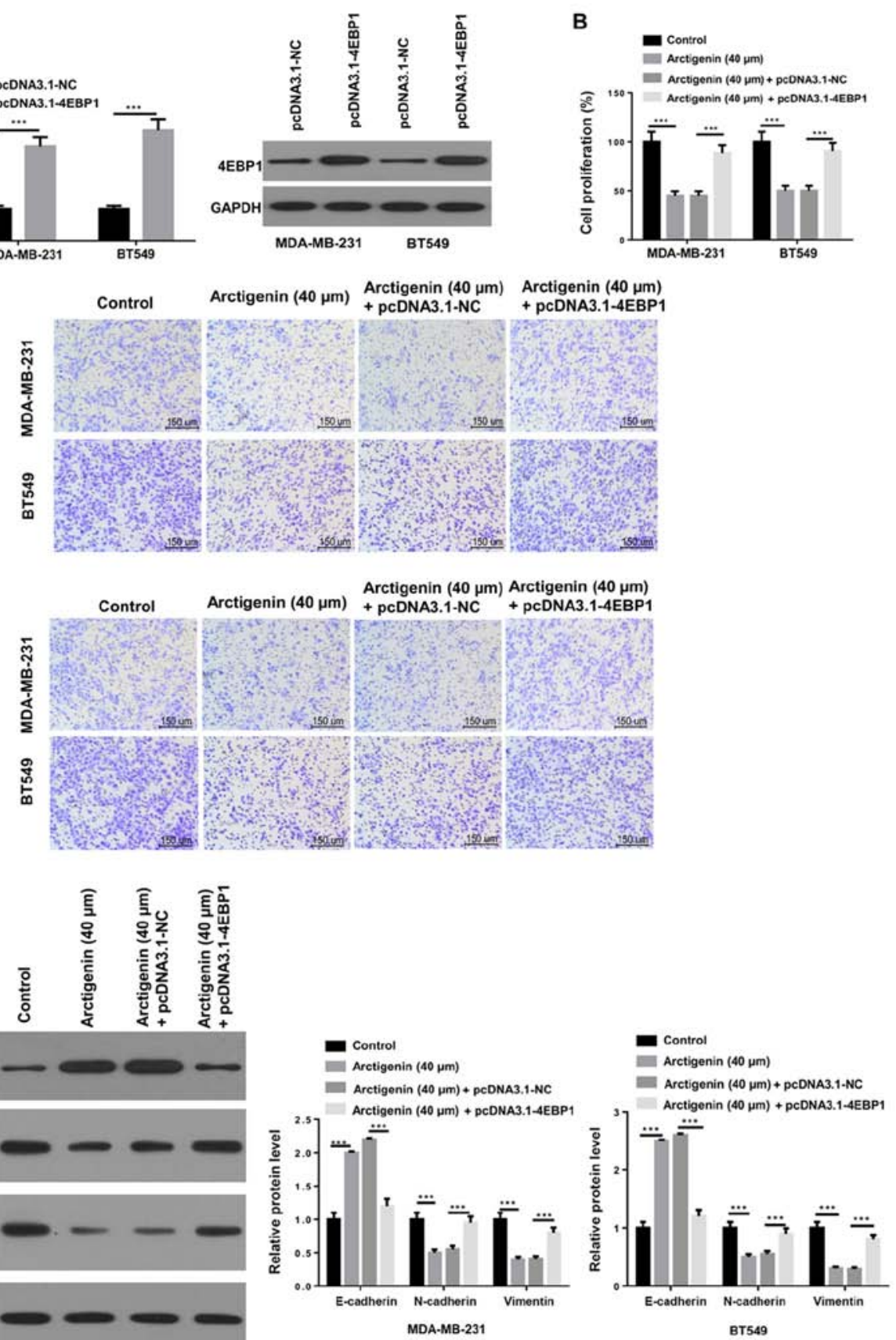

Figure 4. 4EBP1 overexpression could reverse the inhibitory effect of arctigenin on the proliferation, migratory and invasive abilities and EMT in MDA-MB-231 and BT549 cells. (A) Transfection efficiency was examined by reverse transcription quantitative PCR and western blotting. (B) Cell proliferation of transfected MDA-MB-231 and BT549 cells treated with arctigenin was detected using Cell Counting-Kit 8 assay. Transwell assay was used to evaluate the (C) migratory ability or (D) invasive ability of MDA-MB-231 and BT549 cells treated with arctigenin and following transfection with pcDNA3.1-NC or pcDNA3.1-4EBP1 (scale bar, $150 \mu \mathrm{m}$ ). (E) Western blotting was used to evaluate the protein expression of E-cadherin, N-cadherin and vimentin in MDA-MB-231 and BT549 cells treated with arctigenin and following transfection with pcDNA3.1-NC or pcDNA3.1-4EBP1. ${ }^{* * *} \mathrm{P}<0.001$ vs. pcDNA3.1-NC group, Control group or Arctigenin $(40 \mu \mathrm{M})+$ pcDNA3.1-NC group.

revealed that arctigenin has anti-viral, anti-inflammatory and anti-tumor activities $(30,31)$. Furthermore, arctigenin was reported to be a therapeutic agent against cancer and to inhibit some oncogenic signaling pathways (32). As demonstrated by Maxwell et al (33), arctigenin has some anti-metastatic effects on human BC cells by inhibiting MMP-9 and urokinase plasminogen activator via the Akt, NF- $\mathrm{KB}$, and MAPK signaling pathways. Lee et al (34) also demonstrated that arctigenin can decrease the proliferation of MCF-7 and MDA-MB-231 human BC cells and induce apoptosis in MCF-7 cells. In the present study, arctigenin inhibited the proliferation and migratory and invasive abilities of MDA-MB-231 and BT549 cells. These results were consistent with the study of Lou et al (18), in which the effect of arctigenin on the inhibition of $\mathrm{BC}$ cell migration and invasion is confirmed. Another study reported that arctigenin can inhibit the proliferation of MDA-MB-231 cells in a dose-dependent manner and from a concentration as low as $0.4 \mu \mathrm{M}$ (19). In the present study, arctigenin was found to inhibit $\mathrm{BC}$ cell proliferation at the low concentration of $5 \mu \mathrm{M}$ and to inhibit BC cell migratory and invasive abilities 
at the low concentration at $20 \mu \mathrm{M}$. The difference may be due to detection methods and cell culture conditions. As reported by $\mathrm{Xu}$ et al (15), arctigenin can inhibit TGF- $\beta$-induced EMT and suppress the progression and metastasis of lung cancer cells. Lu et al (35) also demonstrated that arctigenin can attenuate tumor metastasis by inhibiting EMT in hepatocellular carcinoma. However, only a few studies have investigated the effect of arctigenin on EMT in BC cells. To the best of our knowledge, the present study was the first to demonstrate that arctigenin could inhibit EMT in MDA-MB-231 and BT549 cells.

As a major substrate of mTORC1, 4EBP1 plays an essential role in the regulation of cancer cell proliferation (36). In addition, 4EBP1 can slow tumor progression in phosphatase and tensin homolog (PTEN)-driven prostate cancer (37). Significant upregulation and dephosphorylation of 4EBP1 serve an important role in the promotion of pancreatic cancer cell death (38). The results from these studies suggest that 4EBP1 might serve as a tumor suppressor factor and inhibit the migratory and invasive abilities of various cancer cells. However, only limited studies have investigated the role and underlying mechanism of 4EBP1 in BC cells in the last decades. Conversely, it was reported that integrated analysis of PTEN and p4EBP1 protein levels could be considered as predictors for pathological complete response in patients with HER2-positive BC receiving neoadjuvant therapy (39). Besides, 4EBP1 is considered as an oncogene and was found to be upregulated in BC cells $(23,24)$. The present study demonstrated for the first time that overexpressing 4EBP1 could reverse the inhibitory effect of arctigenin on the proliferation, migratory and invasive abilities and EMT of BC cells. These result suggested that 4EBP1 may promote tumor progression and act as an oncogene in BC. All these results indicated that 4EBP1 might serve different roles in cell proliferation, migration, invasion and EMT in various types of cancer cell. Further investigation is therefore essential.

In summary, the present study demonstrated that arctigenin could inhibit human BC cell proliferation, migratory and invasive abilities and EMT by targeting 4EBP1. These findings may bring a new direction for the development of targeting therapy against $\mathrm{BC}$.

\section{Acknowledgements}

Not applicable.

\section{Funding}

Not applicable.

\section{Availability of data and material}

The datasets used and analyzed during the current study are available from the corresponding author on reasonable request.

\section{Authors' contributions}

WL conducted the majority of the experiments and wrote the manuscript; FW and HLuo conducted experiments, analyzed the data and confirm the authenticity of all the raw data. HLiu designed the study and revised the manuscript. All authors read and approved the final version of the manuscript.

\section{Ethics approval and consent to participate}

Not applicable.

\section{Patient consent for publication}

Not applicable.

\section{Competing interests}

The authors declare that they have no competing interests.

\section{References}

1. Mavaddat N, Michailidou K, Dennis J, Lush M, Fachal L, Lee A, Tyrer JP, Chen TH, Wang Q, Bolla MK, et al: Polygenic risk scores for prediction of breast cancer and breast cancer subtypes. Am J Hum Genet 104: 21-34, 2019.

2. Shi J, Wu L, Zheng W, Wen W, Wang S, Shu X, Long J, Shen CY, Wu PE, Saloustros E, et al: Genetic evidence for the association between schizophrenia and breast cancer. J Psychiatry Brain Sci 3: 7, 2018.

3. den Bossche JV: Lipid-laden macrophages cross the border to cancer. Immunometabolism 2: e200006, 2020.

4. Sudharshan PJ, Petitjean C, Spanhol F, Oliveira LE, Heutte L and Honeine P: Multiple instance learning for histopathological breast cancer image classification. Exp Syst Appl 117: 103-111, 2019.

5. Sachs N, de Ligt J, Kopper O, Gogola E, Bounova G, Weeber F, Balgobind AV, Wind $\mathrm{K}$, Gracanin A, Begthel $\mathrm{H}$, et al: A living biobank of breast cancer organoids captures disease heterogeneity. Cell 172: 373-386.e10, 2018

6. Turner NC, Slamon DJ, Ro J, Bondarenko I, Im SA, Masuda N, Colleoni M, DeMichele A, Loi S, Verma S, et al: Overall survival with palbociclib and fulvestrant in advanced breast cancer. $\mathrm{N}$ Engl J Med 379: 1926-1936, 2018.

7. Wang X, Qi Y, Kong X, Zhai J, Li Y, Song Y, Wang J, Feng X and Fang Y: Immunological therapy: A novel thriving area for triple-negative breast cancer treatment. Cancer Lett 442: 409-428, 2019.

8. Zhang X, Song W, Zhou Y, Mao F, Lin Y, Guan J and Sun Q: Expression and function of MutT homolog 1 in distinct subtypes of breast cancer. Oncol Lett 13: 2161-2168, 2017.

9. Toi M, Tanaka S, Bando M, Hayashi K and Tominaga T: Outcome of surgical resection for chest wall recurrence in breast cancer patients. J Surg Oncol 64: 23-26, 1997.

10. Waks AG and Winer EP: Breast cancer treatment: A review. JAMA 321: 288-300, 2019.

11. Maxwell T, Lee KS, Kim S and Nam KS: Arctigenin inhibits the activation of the mTOR pathway, resulting in autophagic cell death and decreased ER expression in ER-positive human breast cancer cells. Int J Oncol 52: 1339-1349, 2018.

12. Huang Q, Qin S, Yuan X, Zhang L, Ji J, Liu X, Ma W, Zhang Y, Liu P, Sun Z, et al: Arctigenin inhibits triple-negative breast cancers by targeting CIP2A to reactivate protein phosphatase 2A. Oncol Rep 38: 598-606, 2017.

13. Zhang M, Cai S, Zuo B, Gong W, Tang Z, Zhou D, Weng M, Qin Y, Wang S, Liu J, et al: Arctigenin induced gallbladder cancer senescence through modulating epidermal growth factor receptor pathway. Tumour Biol 39: 1010428317698359, 2017.

14. Ke N, Liu Q, Pi L, Fang J, Chen L and Chen X: The antitumor function of arctigenin in human retinoblastoma cells is mediated by jagged-1. Mol Med Rep 19: 3642-3648, 2019.

15. Xu Y, Lou Z and Lee SH: Arctigenin represses TGF- $\beta$-induced epithelial mesenchymal transition in human lung cancer cells. Biochem Biophys Res Commun 493: 934-939, 2017.

16. Wang P, Diaz T, Henning S and Vadgama J: Abstract 5253: Arctigenin inhibits prostate tumor growth in vitro and in vivo in obese state. Cancer Res 77 (Suppl 13): S5253, 2017. 
17. Wang Y, Lina L, Xu L, Yang Z, Qian Z, Zhou J and Suoni L: Arctigenin enhances the sensitivity of cisplatin resistant colorectal cancer cell by activating autophagy. Biochem Biophys Res Commun 520: 20-26, 2019.

18. Lou C, Zhu Z, Zhao Y, Zhu R and Zhao H: Arctigenin, a lignan from Arctium lappa L., inhibits metastasis of human breast cancer cells through the downregulation of MMP-2/-9 and heparanase in MDA-MB-231 cells. Oncol Rep 37: 179-184, 2017.

19. Feng T, Cao W, Shen W, Zhang L, Gu X, Guo Y, Tsai HI, Liu X, Li J,Zhang J, et al: Arctigenin inhibits STAT3 and exhibits anticancer potential in human triple-negative breast cancer therapy. Oncotarget 8: 329-344, 2017.

20. Zhang T, Guo J, Li H and Wang J: Meta-analysis of the prognostic value of p-4EBP1 in human malignancies. Oncotarget 9 . 2761-2769, 2017

21. Wang Z, Feng X, Molinolo AA, Martin D, Vitale-Cross L, Nohata N, Ando M, Wahba A, Amornphimoltham P, Wu X, et al: 4E-BP1 Is a tumor suppressor protein reactivated by mTOR inhibition in head and neck cancer. Cancer Res 79: 1438-1450, 2019.

22. Alabdullah ML, Ahmad DA, Moseley P, Madhusudan S, Chan S and Rakha E: The mTOR downstream regulator (p-4EBP1) is a novel independent prognostic marker in ovarian cancer. J Obstet Gynaecol 39: 522-528, 2019.

23. Rutkovsky AC, Yeh ES, Guest ST, Findlay VJ, Muise-Helmericks RC, Armeson K and Ethier SP: Eukaryotic initiation factor 4E-binding protein as an oncogene in breast cancer. BMC Cancer 19: 491, 2019.

24. Cristina A, Bartolacci C, Wijnant K, Crinelli R, Bianchi M, Magnani M, Hysi A, Iezzi M, Amici A and Marchini C: Resveratrol fuels HER 2 and ER $\alpha$-positive breast cancer behaving as proteasome inhibitor. Aging (Albany NY) 9: 508-520, 2017.

25. Livak KJ and Schmittgen TD: Analysis of relative gene expression data using real-time quantitative PCR and the 2(-Delta Delta C(T)) method. Methods 25: 402-408, 2001

26. Siegel RL, Miller KD and Jemal A: Cancer statistics, 2019. CA Cancer J Clin 69: 7-34, 2019.

27. Yoon SB and Park HR: Arctigenin inhibits etoposide resistance in HT-29 colon cancer cells during microenvironmental stress. J Microbiol Biotechnol 29: 571-576, 2019.

28. Maheshwari M, Jia Q and Valeriote FA: Arctin and arctigenin as a potential treatment for solid tumors. Cancer Res 79 (Suppl 13): S366, 2019.

29. Naoe A, Tsuchiya T, Kondo Y, Uga N, Watanabe S, Yasui T, Hara F and Suzuki T: Arctigenin induces apoptosis in human hepatoblastoma cells. Pediatr Surg Int 35: 723-728, 2019.
30. Sun Y, Tan YJ, Lu ZZ, Li BB, Sun CH, Li T, Zhao LL, Liu Z, Zhang GM, Yao JC and Li J: Arctigenin inhibits liver cancer tumorigenesis by inhibiting gankyrin expression via $\mathrm{C} / \mathrm{EBP} \alpha$ and PPAR $\alpha$. Front Pharmacol 9: 268, 2018.

31. Lin CY, Hsieh PL, Liao YW, Peng CY, Yu CC and Lu MY: Arctigenin reduces myofibroblast activities in oral submucous fibrosis by LINC00974 inhibition. Int J Mol Sci 20: 13282019.

32. He Y, Fan Q, Cai T, Huang W, Xie X, Wen Y and Shi Z: Molecular mechanisms of the action of arctigenin in cancer. Biomed Pharmacother 108: 403-407, 2018.

33. Maxwell T, Chun SY, Lee KS, Kim S and Nam KS: The anti-metastatic effects of the phytoestrogen arctigenin on human breast cancer cell lines regardless of the status of ER expression. Int J Oncol 50: 727-735, 2017

34. Lee J, Imm JY and Lee SH: $\beta$-catenin mediates anti-adipogenic and anticancer effects of arctigenin in preadipocytes and breast cancer cells. J Agric Food Chem 65: 2513-2520, 2017.

35. Lu Z, Chang L, Zhou H, Liu X, Li Y, Mi T and Tong D: Arctigenin attenuates tumor metastasis through inhibiting epithelial-mesenchymal transition in hepatocellular carcinoma via suppressing GSK3 $\beta$-dependent Wnt/ $\beta$-catenin signaling pathway in vivo and in vitro. Front Pharmacol 10: 937, 2019

36. Wang H, Huang F, Zhang Z, Wang P, Luo Y, Li H, Li N, Wang J, Zhou J, Wang Y and Li S: Feedback activation of SGK3 and AKT contributes to rapamycin resistance by reactivating mTORC1/4EBP1 axis via TSC2 in breast cancer. Int J Biol Sci 15: 929-941, 2019.

37. Ding M, Van der Kwast TH, Vellanki RN, Foltz WD, McKee TD, Sonenberg N, Pandolfi PP, Koritzinsky M and Wouters BG: The mTOR targets $4 \mathrm{E}-\mathrm{BP} 1 / 2$ restrain tumor growth and promote hypoxia tolerance in PTEN-driven prostate cancer. Mol Cancer Res 16: 682-695, 2018

38. Elia A, Henry-Grant R, Adiseshiah C, Marboeuf C, Buckley RJ, Clemens MJ, Mudan S and Pyronnet S: Implication of 4E-BP1 protein dephosphorylation and accumulation in pancreatic cancer cell death induced by combined gemcitabine and TRAIL. Cell Death Dis 8: 3204, 2017.

39. Loibl S, Darb-Esfahani S, Huober J, Klimowicz A, Furlanetto J, Lederer B, Hartmann A, Eidtmann H, Pfitzner B, Fasching PA, et al: Integrated analysis of PTEN and p4EBP1 protein expression as predictors for pCR in HER2-positive breast cancer. Clin Cancer Res 22: 2675-2683, 2016.

This work is licensed under a Creative Commons Attribution-NonCommercial-NoDerivatives 4.0 International (CC BY-NC-ND 4.0) License. 